\title{
BMJ Open Association between adiponectin levels and endometrial carcinoma risk: evidence from a dose-response meta-analysis
}

\author{
Tong Lin, ${ }^{1}$ Xin Zhao, ${ }^{1}$ Wei-min Kong ${ }^{2}$
}

To cite: Lin T, Zhao X, Kong W-min. Association between adiponectin levels and endometrial carcinoma risk: evidence from a doseresponse meta-analysis. BMJ Open 2015;5:e008541. doi:10.1136/bmjopen-2015008541

- Prepublication history for this paper is available online. To view these files please visit the journal online (http://dx.doi.org/10.1136/ bmjopen-2015-008541).

Received 21 April 2015 Revised 24 July 2015 Accepted 5 August 2015

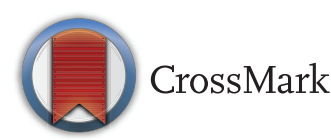

${ }^{1}$ Department of Obstetrics and Gynecology, East Hospital of Beijing University of Traditional Chinese Medicine, Beijing, China ${ }^{2}$ Department of Gynecological Oncology, Beijing Maternity Hospital, Beijing, China

Correspondence to Dr Wei-min Kong; Kwm1967@163.com

\section{ABSTRACT}

Objectives: Epidemiological studies evaluating the association between adiponectin levels and endometrial carcinoma risk have produced inconsistent results. Thus, a meta-analysis was conducted to assess the association between them.

Methods: Pertinent studies were identified by a search of PubMed and Web of Knowledge through January of 2015. A random-effects model was used to combine the data for analysis. Dose-response relationship was assessed by restricted cubic spline and varianceweighted least squares regression analysis.

Results: Twelve articles (5 prospective studies and 7 case-control studies) involving 1916 endometrial carcinoma cases were included in this meta-analysis. Pooled results suggested that highest adiponectin levels versus lowest levels were significantly associated with the risk of endometrial carcinoma (summary relative risk (RR) $=0.525,95 \% \mathrm{Cl} 0.388$ to 0.712 , $\left.\mathrm{I}^{2}=64.2 \%\right)$. The association was also found in postmenopausal women (summary $\mathrm{RR}=0.646,95 \% \mathrm{Cl}$ 0.433 to 0.964 ), but not in premenopausal women. A linear dose-response relationship was found, with the risk of endometrial carcinoma decreasing by $3 \%$ for every $1 \mu \mathrm{g} / \mathrm{mL}$ increase in adiponectin levels (summary RR $=0.97,95 \% \mathrm{Cl} 0.96$ to 0.98 ). No publication bias was found.

Conclusions: Our analysis suggested that the higher adiponectin levels might have a protective effect against endometrial carcinoma, especially in postmenopausal women.

\section{INTRODUCTION}

Cancer is the second leading cause of death in developed countries, behind heart disease. ${ }^{1}$ Endometrial carcinoma is the most common gynaecological malignancy in Europe and North America. The correlation noted between obesity and endometrial cancer cannot be accounted for by the risk posed by elevated levels of endogenous oestrogens alone. It has been postulated that body mass index and other obesity-related

\section{Strengths and limitations of this study}

- Restricted cubic spline and variance-weighted least squares regression analysis assessed dose-response relationship.

- A random-effects model was used to combine the data for analysis.

- The risk of endometrial carcinoma was found to be decreasing by $3 \%$ for every $1 \mu \mathrm{g} / \mathrm{mL}$ increase in adiponectin levels.

factors such as insulin resistance may contribute to an increased risk for endometrial cancer. ${ }^{2}$ Adiponectin, the most abundant circulating adipocytokine, is decreased in obesity, insulin resistance, type 2 diabetes and polycystic ovary syndrome, all of which are independent and well-established risk factors for endometrial cancer. ${ }^{3}$ The relationship between obesity and endometrial carcinoma is complex and likely involves multiple pathways including the sex steroid, insulin and inflammation pathways. ${ }^{4}$ Low levels of adiponectin have been shown to have a high correlation with hyperinsulinaemia and the degree of insulin resistance, independent of adiposity, suggesting that the adiponectin level may serve as a surrogate marker for insulin resistance. ${ }^{5}$ In addition, adiponectin has a longer half-life than most polypeptide hormones, ${ }^{6}$ and circulating levels are not affected significantly by either fasting or oral intake. $^{7}$

As the circulating adiponectin level is an easily monitored marker, and may be useful in prevention and early diagnosis of endometrial cancer, it will be of great importance to clarify the association between adiponectin levels and endometrial cancer risk. ${ }^{8}$ Although there were lines of in vitro and ex vivo evidence for a causal role of adiponectin in endometrial cancer, results from epidemiological studies are inconsistent. ${ }^{8}$ Six 
studies reported an inverse association of adiponectin levels with the risk of endometrial carcinoma. ${ }^{2}$ 9-13 However, six studies found a non-significant association between them. ${ }^{14-19}$ Thus, a meta-analysis was conducted to assess the association between adiponectin levels and endometrial carcinoma risk. We also explore the relevant dose-response association of endometrial carcinoma for every $1 \mu \mathrm{g} / \mathrm{mL}$ increase in adiponectin levels.

\section{METHODS}

\section{Search strategy}

Studies were identified by a literature search of PubMed and Web of Knowledge up to January 2015, and by hand-searching the reference lists of the computer retrieved articles. The following search terms were used: 'endometrial cancer' or 'endometrial carcinoma' combined with 'adiponectin'. Two of the authors independently searched the related articles and reviewed the articles.

\section{Inclusion criteria}

The related articles were included if they matched the following criteria: (1) the studies were of case-control or cohort design; (2) the exposure of interest was adiponectin levels; (3) the end point of the result was endometrial carcinoma; (4) there was sufficient data generated to make a relative risk (RR) of OR with $95 \%$ CIs; and (5) each category of adiponectin levels was also provided for the dose-response analysis.

\section{Data extraction}

Two researchers independently extracted the following data from each study that met the criteria for inclusion: the first author's last name, year of publication, geographic locations, study design, menopausal status, the age range of study participants, and the number of cases and participants (person-years); RRs (95\% CI) for each category of adiponectin levels were also extracted. The most fully adjusted RR and 95\% CI, and statistical adjustment for the main confounding or mediating factors, were extracted. Otherwise, the crude RR (95\% CI) was extracted.

\section{Statistical analysis}

A random-effect meta-analysis was carried out to assess the dose-response relationship between adiponectin levels and endometrial carcinoma using the method suggested by Greenland and Longnecker, ${ }^{2}$ and Orsini and Bellocco, ${ }^{21}$ which considered the relationship between the $\log$ RR estimates among the categories of adiponectin levels. The non-linear relationships was also assessed by modelling adiponectin levels using restricted cubic splines with three knots at the fixed percentiles $(25 \%$, $50 \%$ and $75 \%$ ) of adiponectin level distribution. We calculated the $\mathrm{p}$ value for nonlinearity by testing against the null hypothesis. ${ }^{22}$ For the dose-response analysis, the number of cases and participants or person-years for at least three quantitative exposure categories are available in each study. We will estimate the slopes by using variance-weighted least squares regression analysis when the aforementioned information was not known. ${ }^{23} 24$ The median adiponectin levels were used with each specific category to each corresponding $\log$ RR estimate. The midpoint of adiponectin levels between the upper and lower boundaries was used when the median level was not available. If the upper and lower boundaries of the category were opened, we assumed the category to be of the same amplitude as the preceding one. Heterogeneity across the studies was tested by using the $\mathrm{Q}$ test and $\mathrm{I}^{2}$ statistics. ${ }^{25}$ The $\mathrm{I}^{2}$ was used to assess heterogeneity, and $\mathrm{I}^{2}$ values of $0,25,50$ and $75 \%$ represent no, low, moderate and high heterogeneity, respectively. Meta-regression and subgroup analyses were conducted to explore the potential sources of between-study heterogeneity. ${ }^{26}$ Sensitivity analysis ${ }^{27}$ was performed to describe how robust the pooled RR and 95\% CI are while each individual study was removed. We used the Begg's funnel plot ${ }^{28}$ and Egger's regression test ${ }^{29}$ to evaluate the publication bias.

All the statistical analyses were performed using Stata V.10.0 (Stata Corp, College Station, Texas, USA).

\section{RESULTS}

\section{Search results and study characteristics}

The electronic database searches identified 111 citations. A total of 68 studies were excluded on abstract review. The remaining 43 studies were reviewed for further details. Thirty-one additional studies were excluded for various reasons, as shown in figure 1 . Finally, 12 articles $^{2}{ }^{9-19}$ involving 1916 endometrial carcinoma cases were included in this meta-analysis. The characteristics of these studies are presented in table 1 . Five studies were conducted in the USA, two in Japan, and one each in China, Europe, Canada, Turkey and in Greece.

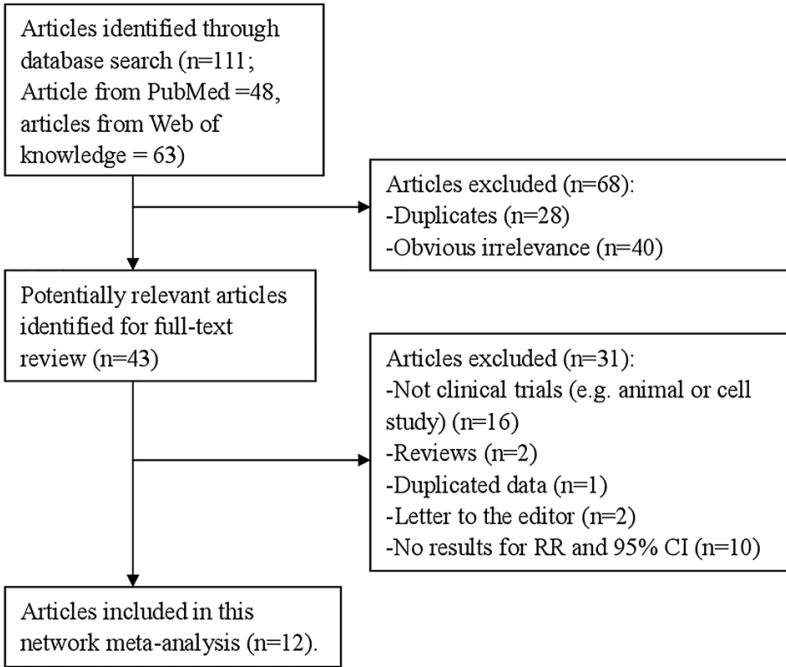

Figure 1 The flow diagram of screened, excluded and analysed publications. $\mathrm{RR}$, relative risk. 
Table 1 Characteristics of studies on adiponectin levels and endometrial carcinoma risk

\begin{tabular}{|c|c|c|c|c|c|}
\hline $\begin{array}{l}\text { First author, } \\
\text { year }\end{array}$ & Country & Study design & Cases, age & Category $(\mu \mathrm{g} / \mathrm{mL})$ & $\begin{array}{l}\text { RR }(95 \% \mathrm{Cl}) \text { for } \\
\text { each category }\end{array}$ \\
\hline Ashizawa, 2010 & Japan & Case-control & $146,58.7$ & $\begin{array}{l}<5.2 \\
5.2-10.3 \\
\geq 10.3\end{array}$ & $\begin{array}{l}1 \\
0.9(0.5 \text { to } 1.6) \\
0.6(0.3 \text { to } 1.2)\end{array}$ \\
\hline Cust, 2007 & Europe & Prospective & 284,51 & $\begin{array}{l}<7.3 \\
7.3-10.2 \\
10.3-13.5 \\
\geq 13.6\end{array}$ & $\begin{array}{l}1 \\
0.84(0.53 \text { to } 1.34) \\
0.67(0.41 \text { to } 1.11) \\
0.63(0.36 \text { to } 1.10)\end{array}$ \\
\hline Dallal, 2013 & USA & Prospective & $62,55-80$ & $\begin{array}{l}\leq 11.67 \\
11.68-18.0 \\
\geq 18.1\end{array}$ & $\begin{array}{l}1 \\
1.48(0.69 \text { to } 3.18) \\
1.00(0.44 \text { to } 2.31)\end{array}$ \\
\hline Dal Maso, 2004 & USA & Case-control & $87,34-78$ & $\begin{array}{l}<10 \\
10-18 \\
\geq 19\end{array}$ & $\begin{array}{l}1 \\
0.51(0.24 \text { to } 1.08) \\
0.42(0.14 \text { to } 0.94)\end{array}$ \\
\hline Erdogan, 2013 & Turkey & Prospective & $60,53.1$ & $\begin{array}{l}<10.91 \\
10.91-21.14 \\
>21.14\end{array}$ & $\begin{array}{l}1 \\
0.62(0.12 \text { to } 3.37) \\
0.09(0.02 \text { to } 0.36)\end{array}$ \\
\hline $\begin{array}{l}\text { Friedenreich, } \\
2012\end{array}$ & Canada & Case-control & 514,59 & $\begin{array}{l}\leq 10 \\
10.0-14.6 \\
14.6-21.5 \\
>21.5\end{array}$ & $\begin{array}{l}1 \\
0.69(0.50 \text { to } 0.94) \\
0.75(0.54 \text { to } 1.05) \\
0.55(0.37 \text { to } 0.80)\end{array}$ \\
\hline Luhn, 2013 & USA & Prospective & $167,55-74$ & $\begin{array}{l}\leq 11.89 \\
11.90-18.10 \\
>18.10\end{array}$ & $\begin{array}{l}1 \\
0.54(0.34 \text { to } 0.87) \\
0.48(0.29 \text { to } 0.80)\end{array}$ \\
\hline $\mathrm{Ma}, 2013$ & China & Case-control & $206,26-81$ & $\begin{array}{l}\text { T1 } \\
\text { T2 } \\
\text { T3 }\end{array}$ & $\begin{array}{l}1 \\
0.81(0.51 \text { to } 1.28) \\
0.52(0.32 \text { to } 0.83)\end{array}$ \\
\hline Ohbuchi, 2013 & Japan & Case-control & $43,39-82$ & Highest vs lowest & 0.50 (0.10 to 3.45$)$ \\
\hline Petridou, 2003 & Greece & Case-control & $84,<55->75$ & Highest vs lowest & 0.78 (0.56 to 1.10$)$ \\
\hline $\begin{array}{l}\text { Soliman, } 2006 \\
\text { Soliman, } 2011\end{array}$ & $\begin{array}{l}\text { USA } \\
\text { USA }\end{array}$ & $\begin{array}{l}\text { Case-control } \\
\text { Prospective }\end{array}$ & $\begin{array}{l}117,25-88 \\
146,64.6\end{array}$ & $\begin{array}{l}\text { Highest vs lowest } \\
<10.00 \\
10.00-14.99 \\
\geq 15.00\end{array}$ & $\begin{array}{l}0.10(0.04 \text { to } 0.24) \\
1 \\
0.74(0.43 \text { to } 1.28) \\
0.98(0.57 \text { to } 1.68)\end{array}$ \\
\hline
\end{tabular}

Adjustment for covariates

Adjustment for age, BMI, hypertension, and diabetes mellitus

Adjustment for BMI, C-peptide, IGFBP-1, IGFBP-2, SHBG, oestrone, free testosterone

Adjustment for age at baseline/blood draw \pm 5 years, clinic site, time of blood draw $\pm 2 \mathrm{~h}$, trial participation status; controls selected from non-cases alive and disease free at the time of diagnosis of the case and with an intact uterus at FIT baseline

Adjustment for age, education, parity, smoking status, BMI, and hormone replacement therapy

Adjustment for age, BMI, HOMA-IR and QUICKI

Adjustment for age at reference, nulliparous (vs multiparous) HRT, menopausal hormone use, hypertension, weight at reference date, and waist-to-hip ratio

Adjustment for family history of breast or endometrial cancer education level, parity, history of diabetes diagnosis, oral contraceptive use, and current smoking status

Adjustment for body mass index, glucose (GLU), cholesterol, triglycerides, high-density lipoprotein cholesterol, age, insulin and leptin-to-adiponectin (L/A)

Adjustment for age, BMI, hypertension, and diabetes mellitus.

Adjustment for sociodemographic, reproductive, and relevant hormonal variables

Adjustment for age, BMI, hypertension, and diabetes Adjustment for BMI at blood draw(continuous), parity (nulliparous (reference), 1-2 and age at last birth $<30,1-2$ and age at last birth $>=30,3-4$ and age at last birth $<30,3-4$ and age at last birth $>=30,5+$ ), diabetes (yes, no)

BMI, body mass index; FIT, Fracture Intervention Trial; HRT, hormone replacement therapy; IGFBP-1, insulin-like growth factor binding protein 1; SHBG, sex hormone binding globulin; $\mathrm{RR}$, relative risk. 
Figure 2 The forest plot between highest versus lowest categories of adiponectin levels and endometrial carcinoma risk.

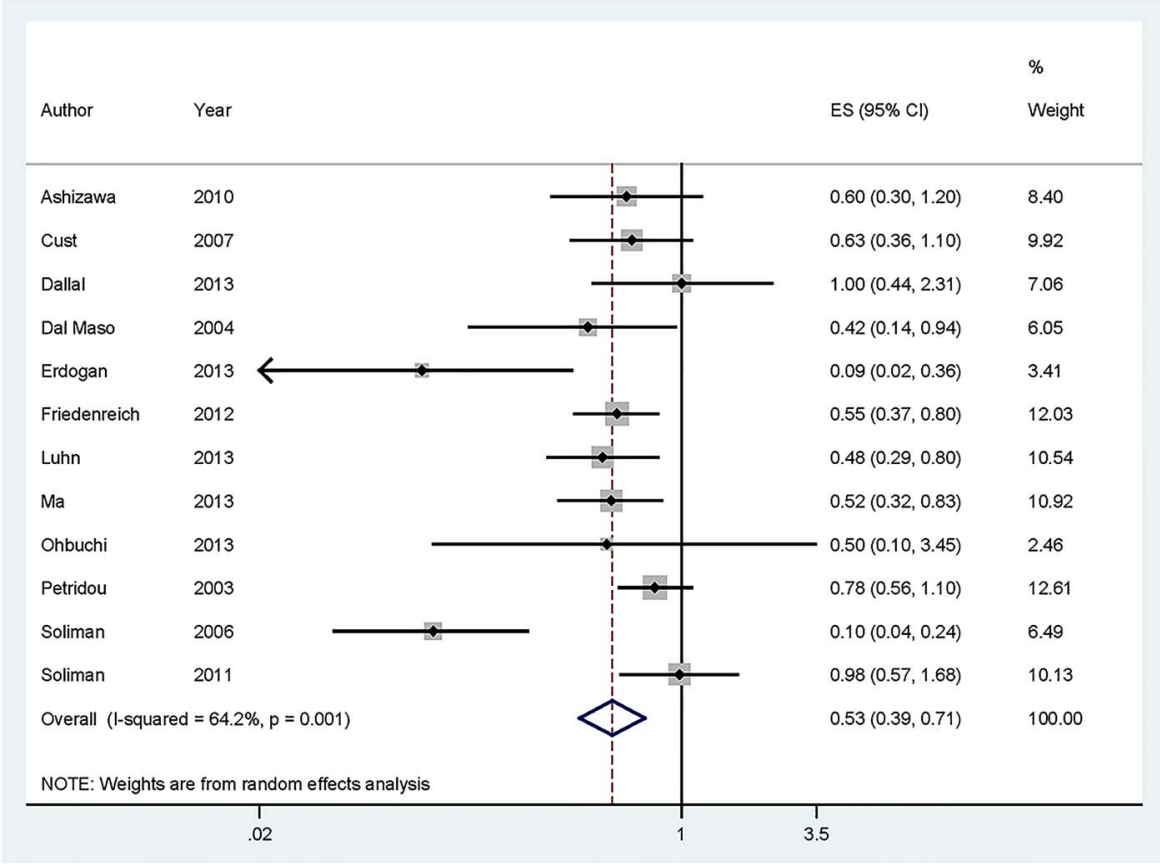

\section{Highest versus lowest adiponectin levels}

Six of the studies included in our analysis reported an inverse association of adiponectin levels with the risk of endometrial carcinoma, while no significant association was reported in six studies. Our pooled results suggested that the highest adiponectin levels compared to the lowest levels were significantly associated with the risk of endometrial carcinoma (summary $\mathrm{RR}=0.525,95 \%$ CI 0.388 to $0.712, \mathrm{I}^{2}=64.2 \%$ ) (figure 2 ).

When the studies were stratified by study design, the associations were found in the prospective studies (summary $\mathrm{RR}=0.593,95 \%$ CI 0.352 to 0.834 ) and casecontrol studies (summary $\mathrm{RR}=0.475,95 \%$ CI 0.316 to 0.712 ). In subgroup analyses for menopausal status, an inverse association of adiponectin levels with risk of endometrial carcinoma was found in postmenopausal women (summary $\mathrm{RR}=0.646,95 \%$ CI 0.433 to 0.964 ), but not in premenopausal women. When we conducted a subgroup analysis by geographic locations, significant associations were also found in America, Europe and Asia. Detailed results are summarised in table 2.

\section{Dose-response analysis}

For dose-response analysis, data from eight studies ${ }^{9-12}$ 14-16 19 comprising 1466 cases were used for adiponectin levels and endometrial carcinoma risk. We found no evidence of statistically significant departure from linearity ( $p$ for nonlinearity $=0.44$ ). Our dose-response analysis indicated that an increase in adiponectin levels of $1 \mu \mathrm{g} / \mathrm{mL}$ was statistically significantly associated with a $3 \%$ decrease in the risk of developing endometrial carcinoma (summary $\mathrm{RR}=0.97$, $95 \%$ CI 0.96 to 0.98 ; figure 3 ).

\section{Meta-regression analysis}

We found evidence of heterogeneity $\left(\mathrm{I}^{2}=64.2 \%\right.$, $\left.\mathrm{P}_{\text {heterogeneity }}=0.001\right)$ in the pooled results. To explore the moderate to high between-study heterogeneity found in several analysis, univariate meta-regression with the

Table 2 Summary risk estimates of the association between adiponectin levels and endometrial carcinoma risk

\begin{tabular}{|c|c|c|c|c|c|}
\hline Subgroups & Cases & Studies & RR (95\% Cl) & $I^{2}(\%)$ & $\mathbf{P}_{\text {heterogeneity }}$ \\
\hline All studies & 1916 & 12 & 0.525 (0.388 to 0.712$)$ & 64.2 & 0.001 \\
\hline \multicolumn{6}{|l|}{ Menopausal status } \\
\hline Premenopausal & 179 & 4 & $0.636(0.343$ to 1.181$)$ & 38.8 & 0.179 \\
\hline Postmenopausal & 811 & 8 & $0.646(0.433$ to 0.964$)$ & 59.5 & 0.016 \\
\hline \multicolumn{6}{|l|}{ Study design } \\
\hline Prospective & 719 & 5 & $0.593(0.352$ to 0.834$)$ & 66.1 & 0.019 \\
\hline Case-control & 1197 & 7 & $0.475(0.316$ to 0.712$)$ & 67.4 & 0.005 \\
\hline \multicolumn{6}{|l|}{ Geographic locations } \\
\hline America & 1093 & 6 & 0.497 (0.295 to 0.838$)$ & 76.1 & 0.001 \\
\hline Europe & 368 & 2 & 0.737 (0.552 to 0.983$)$ & 0.0 & 0.521 \\
\hline Asia & 455 & 4 & 0.426 (0.229 to 0.791$)$ & 47.0 & 0.129 \\
\hline
\end{tabular}




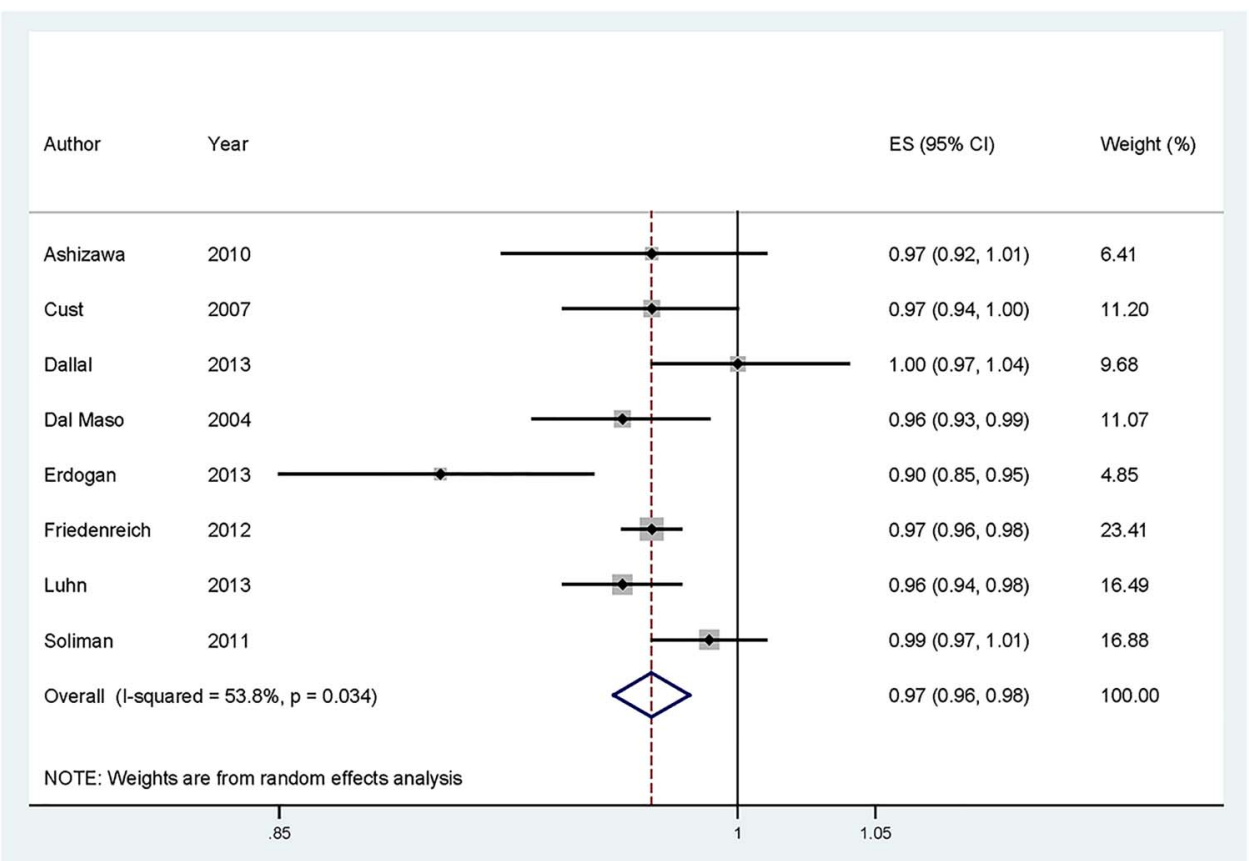

Figure 3 Dose-response meta-analyses of every $1 \mu \mathrm{g} / \mathrm{mL}$ increase in adiponectin levels and the risk of endometrial carcinoma. Squares represent study-specific $\mathrm{RR}$, horizontal lines represent $95 \% \mathrm{Cl}$ and diamonds represent summary relative risks. $\mathrm{RR}$, relative risk.

covariates of publication year, location where the study was conducted, study design (case-control or prospective), menopausal status and number of cases was performed. However, the univariate meta-regression could not find any significant results.

\section{Sensitivity analysis and publication bias}

Sensitivity analysis showed that no study had excessive influence between the association of adiponectin levels and endometrial carcinoma risk. Begg's funnel plot (figure 4) and Egger's test ( $\mathrm{p}=0.199)$ did not find any significant publication bias between adiponectin levels and the risk of endometrial carcinoma.

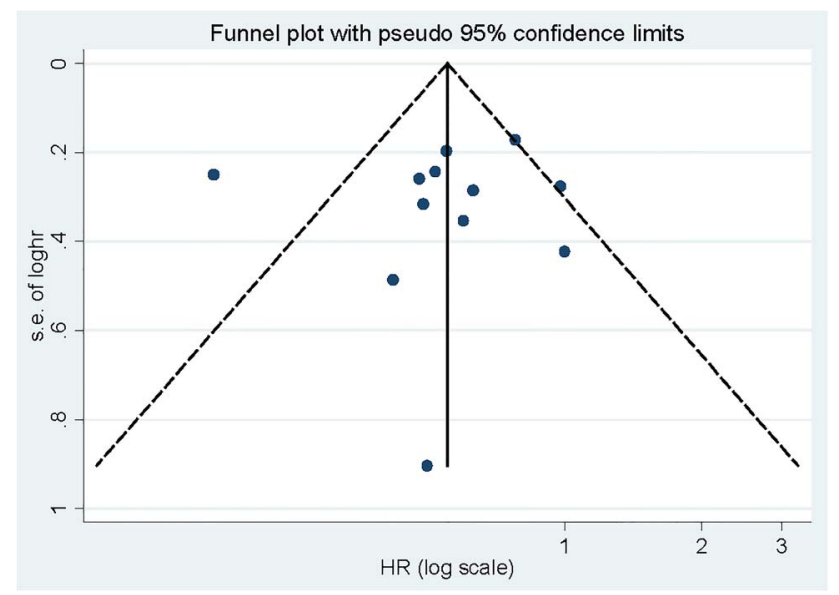

Figure 4 Begg's funnel plot for publication bias of adiponectin levels and endometrial carcinoma risk.

\section{DISCUSSION}

Findings from this study indicated that highest the adiponectin levels versus lowest levels were significantly associated with the risk of endometrial carcinoma, especially in postmenopausal women. Inverse associations were also found in the subgroup of America, Europe and Asia. Our dose-response analysis demonstrated a linear relationship between adiponectin levels and the risk of endometrial carcinoma, with a decrease in risk of $3 \%$ for every $1 \mu \mathrm{g} / \mathrm{mL}$ increase in adiponectin levels.

Adipose tissue is an active endocrine organ that releases a number of cytokines and hormones, collectively termed adipocytokines, including adiponectin, leptin and resistin. ${ }^{30}$ Adiponectin, the most abundant circulating adipocytokine, is decreased in obesity, insulin resistance, type 2 diabetes and polycystic ovary syndrome, all of which are independent and wellestablished risk factors for endometrial cancer. ${ }^{3}$ One major metabolic pathway through which adiponectin could influence endometrial cancer risk is by decreasing blood insulin and glucose levels, mainly through increased fatty acid oxidation in skeletal muscle, inhibition of hepatic glucose production, improved insulin signal transduction and increased peripheral tissue sensitivity to insulin. ${ }^{31} 32$ Circulating insulin and glucose levels are associated with increased endometrial cancer risk. ${ }^{33}$

Munafo and Flint ${ }^{34}$ reported that between-study heterogeneity is common in meta-analyses. Exploring potential sources of between-study heterogeneity is therefore an essential component of meta-analysis. We found a moderate degree of heterogeneity $\left(\mathrm{I}^{2}=64.2 \%\right.$, 
$\left.P_{\text {heterogeneity }}=0.001\right)$ in our pooled results. This might have arisen from publication year, location where the study was conducted, study design (case-control or prospective), menopausal status and number of cases. Thus, we used meta-regression to explore the causes of heterogeneity for covariates. However, no covariate having a significant impact on between-study heterogeneity was found among those mentioned above. We then performed subgroup analyses by the type of study design (prospective or case-control studies), geographic locations and menopausal status, to explore the source of heterogeneity. However, between-study heterogeneity persisted in some of the subgroups, suggesting the presence of other unknown confounding factors. Since we could not control the information of each individual study, the 12 studies included used different definitions for highest and lowest adiponectin levels (eg, quartiles or tertiles), different specimens (plasma or serum) and different detection systems, etc. These differences should influence on the results.

As a meta-analysis of published studies, our findings showed some advantages. First, the major highlight of this study is that we found a linear dose-response analysis between adiponectin levels and the risk of endometrial carcinoma. The risk of endometrial cancer decreased by $3 \%$ for every $1 \mu \mathrm{g} / \mathrm{mL}$ increase in adiponectin levels. Second, a large number of cases and participants were included, greatly increasing the possibility of reaching reasonable conclusions between adiponectin levels and endometrial carcinoma risk. Third, no significant publication bias was found, indicating that our results are stable. However, there were some limitations in this meta-analysis. First, a meta-analysis of observational studies is susceptible to potential bias inherent in the original studies, especially for case-control studies. Overstated association may be expected from the casecontrol studies because of recall or selection bias, and early symptoms in patients may have resulted in a change in dietary habits. However, significant associations were found both in case-control studies and prospective studies. More future studies of prospective design are needed; only five studies included in this meta-analysis were of a prospective design. Second, for the subgroup analysis of geographic locations, although significance was found in America, Europe and Asia, only two studies came from Europe. Owing to this limitation, more studies originating in geographic locations of Europe are required to investigate the association between adiponectin levels and endometrial carcinoma risk. Third, between-study heterogeneity was found in some analyses used in this meta-analysis, but the between-study heterogeneity was not successfully explained by meta-regression and subgroup analysis. However, other genetic and environment variables, as well as their possible interaction, may be potential contributors to this disease-effect unconformity.

In summary, results from this meta-analysis suggested that higher adiponectin levels might have a protective effect against endometrial carcinoma, especially in postmenopausal women. Dose-response analysis indicated that the risk decrease in endometrial carcinoma is estimated at $3 \%$ for every $1 \mu \mathrm{g} / \mathrm{mL}$ increase in adiponectin levels.

Contributors WK and TL conceived of and designed the study. TL and XZ performed the study. TL analysed the data and wrote the paper. WK critically revised the manuscript.

Competing interests None declared.

Provenance and peer review Not commissioned; externally peer reviewed.

Data sharing statement No additional data are available.

Open Access This is an Open Access article distributed in accordance with the Creative Commons Attribution Non Commercial (CC BY-NC 4.0) license, which permits others to distribute, remix, adapt, build upon this work noncommercially, and license their derivative works on different terms, provided the original work is properly cited and the use is non-commercial. See: http:// creativecommons.org/licenses/by-nc/4.0/

\section{REFERENCES}

1. Jemal A, Ward E, Hao Y, et al. Trends in the leading causes of death in the United States, 1970-2002. JAMA 2005;294:1255-9.

2. Soliman PT, Wu D, Tortolero-Luna G, et al. Association between adiponectin, insulin resistance, and endometrial cancer. Cancer 2006;106:2376-81.

3. Kaaks R, Lukanova A, Kurzer MS. Obesity, endogenous hormones, and endometrial cancer risk: a synthetic review. Cancer Epidemiol Biomarkers Prev 2002;11:1531-43.

4. Gunter MJ, Hoover DR, $\mathrm{Yu} \mathrm{H}$, et al. A prospective evaluation of insulin and insulin-like growth factor-I as risk factors for endometrial cancer. Cancer Epidemiol Biomarkers Prev 2008;17:921-9.

5. Weyer C, Funahashi T, Tanaka S, et al. Hypoadiponectinemia in obesity and type 2 diabetes: close association with insulin resistance and hyperinsulinemia. J Clin Endocrinol Metab 2001;86:1930-5.

6. Hoffstedt J, Arvidsson E, Sjolin E, et al. Adipose tissue adiponectin production and adiponectin serum concentration in human obesity and insulin resistance. J Clin Endocrinol Metab 2004;89:1391-6.

7. Gavrila A, Chan JL, Yiannakouris N, et al. Serum adiponectin levels are inversely associated with overall and central fat distribution but are not directly regulated by acute fasting or leptin administration in humans: cross-sectional and interventional studies. J Clin Endocrinol Metab 2003;88:4823-31.

8. Moon HS, Chamberland JP, Aronis K, et al. Direct role of adiponectin and adiponectin receptors in endometrial cancer: in vitro and ex vivo studies in humans. Mol Cancer Ther 2011;10:2234-43.

9. Dal Maso L, Augustin LS, Karalis A, et al. Circulating adiponectin and endometrial cancer risk. J Clin Endocrinol Metab 2004;89:1160-3.

10. Erdogan S, Sezer S, Baser E, et al. Evaluating vaspin and adiponectin in postmenopausal women with endometrial cancer. Endocr Relat Cancer 2013;20:669-75.

11. Friedenreich CM, Langley AR, Speidel TP, et al. Case-control study of markers of insulin resistance and endometrial cancer risk. Endocr Relat Cancer 2012;19:785-92.

12. Luhn P, Dallal CM, Weiss JM, et al. Circulating adipokine levels and endometrial cancer risk in the prostate, lung, colorectal, and ovarian cancer screening trial. Cancer Epidemiol Biomarkers Prev 2013;22:1304-12.

13. Ma Y, Liu Z, Zhang $Y$, et al. Serum leptin, adiponectin and endometrial cancer risk in Chinese women. J Gynecol Oncol 2013;24:336-41.

14. Ashizawa N, Yahata T, Quan J, et al. Serum leptin-adiponectin ratio and endometrial cancer risk in postmenopausal female subjects. Gynecol Oncol 2010;119:65-9.

15. Cust AE, Kaaks $R$, Friedenreich $C$, et al. Plasma adiponectin levels and endometrial cancer risk in pre- and postmenopausal women. J Clin Endocrinol Metab 2007;92:255-63.

16. Dallal CM, Brinton LA, Bauer DC, et al. Obesity-related hormones and endometrial cancer among postmenopausal women: a nested case-control study within the B FIT cohort. Endocr Relat Cancer 2013:20:151-60.

17. Ohbuchi Y, Suzuki Y, Hatakeyama I, et al. A lower serum level of middle-molecular-weight adiponectin is a risk factor for endometrial cancer. Int J Clin Oncol 2014;19:667-73. 
18. Petridou E, Mantzoros C, Dessypris N, et al. Plasma adiponectin concentrations in relation to endometrial cancer: a case-control study in Greece. J Clin Endocrinol Metab 2003;88:993-7.

19. Soliman PT, Cui X, Zhang Q, et al. Circulating adiponectin levels and risk of endometrial cancer: the prospective Nurses' Health Study. Am J Obstet Gynecol 2011;204:167 e1-5.

20. Greenland S, Longnecker MP. Methods for trend estimation from summarized dose-response data, with applications to meta-analysis. Am J Epidemiol 1992;135:1301-9.

21. Orsini N, Bellocco R. Generalized least squares for trend estimation of summarized dose-response data. Stata J 2006;6:40-57.

22. Orsini N, Li R, Wolk A, et al. Meta-analysis for linear and nonlinear dose-response relations: examples, an evaluation of approximations, and software. Am J Epidemiol 2012;175:66-73.

23. Larsson SC, Giovannucci E, Wolk A. Folate and risk of breast cancer: a meta-analysis. J Natl Cancer Inst 2007;99:64-76.

24. Chen $\mathrm{H}$, Qin S, Wang M, et al. Association between cholesterol intake and pancreatic cancer risk: evidence from a meta-analysis. Sci Rep 2015;5:8243.

25. Higgins JP, Thompson SG. Quantifying heterogeneity in a meta-analysis. Stat Med 2002;21:1539-58.
26. Higgins JP, Thompson SG. Controlling the risk of spurious findings from meta-regression. Stat Med 2004;23:1663-82.

27. Tobias A. Assessing the in fluence of a single study in the meta-analysis estimate. Stata Tech Bull 1999;47:15-17.

28. Begg CB, Mazumdar M. Operating characteristics of a rank correlation test for publication bias. Biometrics 1994;50:1088-101.

29. Egger M, Davey Smith G, Schneider M, et al. Bias in meta-analysis detected by a simple, graphical test. BMJ 1997;315:629-34.

30. Kadowaki T, Yamauchi T. Adiponectin and adiponectin receptors. Endocr Rev 2005;26:439-51.

31. Yamauchi T, Kamon J, Waki $\mathrm{H}$, et al. The fat-derived hormone adiponectin reverses insulin resistance associated with both lipoatrophy and obesity. Nat Med 2001;7:941-6.

32. Maeda N, Shimomura I, Kishida K, et al. Diet-induced insulin resistance in mice lacking adiponectin/ACRP30. Nat Med 2002;8:731-7.

33. Lukanova A, Zeleniuch-Jacquotte A, Lundin E, et al. Prediagnostic levels of C-peptide, IGF-I, IGFBP $-1,-2$ and -3 and risk of endometrial cancer. Int J Cancer 2004;108:262-8.

34. Munafo MR, Flint J. Meta-analysis of genetic association studies. Trends Genet 2004;20:439-44. 


\section{Correction}

Lin T, Zhao X, Kong W-min. Association between adiponectin levels and endometrial carcinoma risk: evidence from a dose-response meta-analysis. BMJ Open 2015;5: e008541. The institutional affiliation for the last author of this paper, Wei-min Kong, was published incorrectly. The correct affiliation for Wei-min Kong is: Department of Gynecological Oncology, Beijing Obstetrics and Gynecology Hospital, Capital Medical University, Beijing, China.

BMJ Open 2016;6:e008541corr1. doi:10.1136/bmjopen-2015-008541corr1

CrossMark 